\title{
A Survey Paper on Security Challenges in Healthcare Cloud Computing
}

\author{
Shalini G* \\ Dept of CSE, Dr TTIT, KGF
}

DOI: https://doi.org/10.21467/proceedings.1.54

* Corresponding author email: Shalini.reddy.leo@gmail.com

\begin{abstract}
Cloud computing is the BuzzWord of today. Its business models like PaaS, SaaS and IaaS have been some of the biggest changes in todays world impacting not only the computer industry but also several other fields, one such is the health care. Health care industry is slowly moving towards cloud because of the benefits provided by cloud computing. As Patient data are very sensitive records that should not be made available to unauthorized people there comes the challenge of security in order to protect patient's information. However, cloud technology is vulnerable to cyber gaps that pose an adverse impact on the security and privacy of patient's electronic health records and in these situations, security challenges in cloud computing environment are a matter of challenge with rising usage of cloud technology.
\end{abstract}

Index Terms- Cloud computing, Electronic health record, Healthcare data, Security

\section{INTRODUCTION}

Cloud computing is an information technology paradigm that gives on-demand service to its customers. It enables users to access shared pools of configurable system resources ubiquitously. Cloud computing is making its way in many fields and one such is health care. Health care is faster growing its way to adaptation of cloud computing. Cloud-based services are very largely adopted for health care organizations. The real-life businesses and organizations normally build applications in quite a complex environment that involves networking, security, physical server's firewalls etc and they expect same or higher level of service provided by the cloud service providers and the cloud so that their data is protected. Health care industry has been one such field like banking sectors, nuclear energy and government sectors that have extremely strict policies to prevent data theftbecause of which traditionally they prevent outsourcing [1]. Security and privacy of sensitive data is the biggest challenge to be faced by the cloud service providers. This section presents about cloud computing, the need of cloud computing in health care and its impact on health care industry.

(C) 2018 Copyright held by the author(s). Published by AIJR Publisher in Proceedings of the $3^{\text {rd }}$ National Conference on Image Processing, Computing, Communication, Networking and Data Analytics (NCICCNDA 2018), April 28, 2018.

This is an open access article under Creative Commons Attribution-NonCommercial 4.0 International (CC BY-NC 4.0) license, which permits any non-commercial use, distribution, adaptation, and reproduction in any medium, as long as the original work is properly cited. ISBN: $978-81-936820-0-5$ 
A Survey Paper on Security Challenges in Healthcare Cloud Computing

\subsection{Cloud computing}

Cloud Computing provides us a surrounding to share the resources in terms of ascendance frameworks, infrastructure, middleware's and application development platforms, and business applications. The operation models of cloud computing grasp free infrastructure services with value another platform services, subscription-based infrastructure services with supplemental application services for sellers but revenues generated are shared from shoppers [2]. Traditional infrastructure provisioning model is inefficient and does not meet the requirements of the internet era. In this system centric model, once the need for a business application is identified, its infrastructure is placed with the IT infrastructure team that procures and provisions the infrastructure [3]. Fig1 shows the three main service models of cloud: Infrastructure -as- service(Iaas) where a vendor provides clients pay-as-you go access to storage, networking, servers and other computing resources in the cloud. platform -as -a service(Paas)in which users can build and deliver applications and software -as -a- service(Saas) in which a service provider delivers software and applications through the internet.

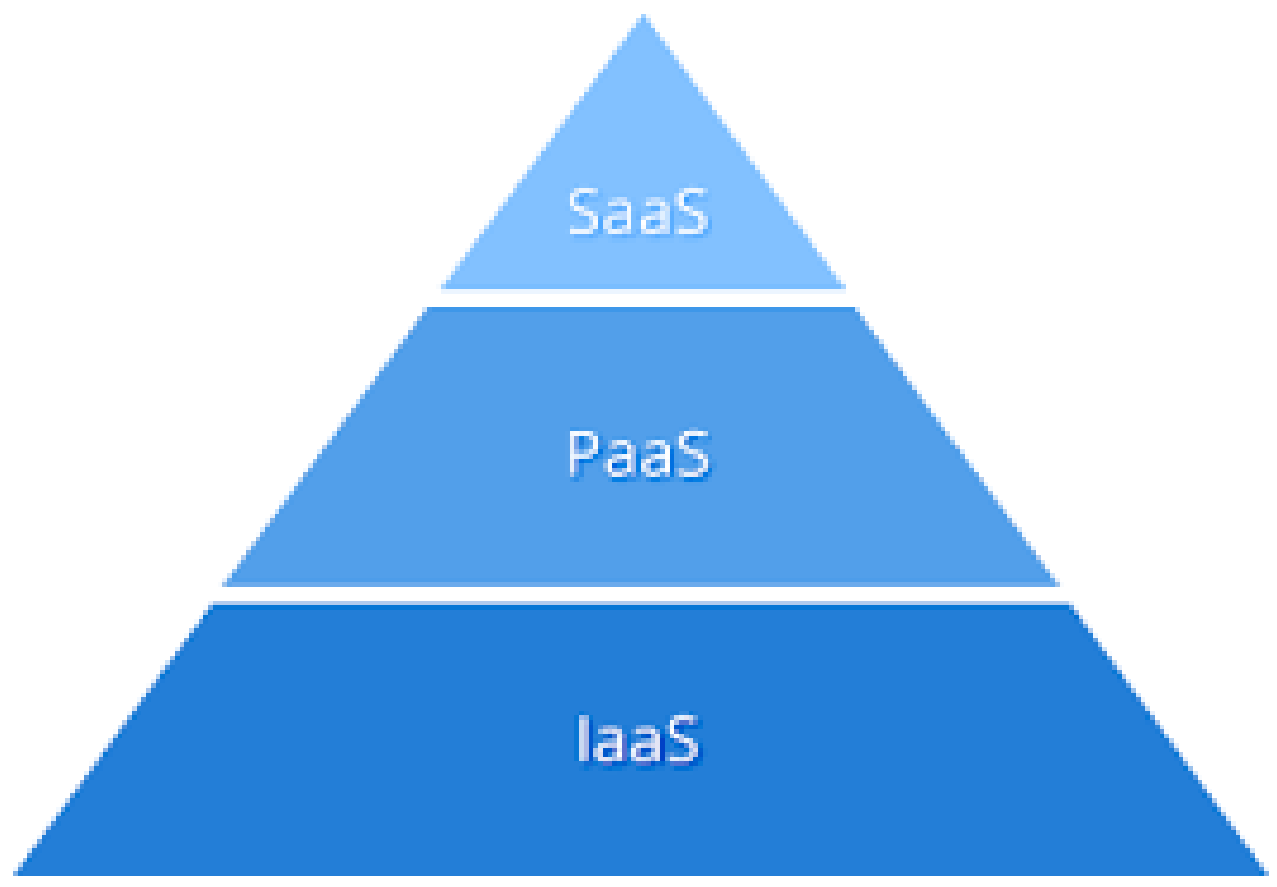

Figure 1:Cloud service models

The characteristics which are beneficial from cloud are its On-demand service where resources can be provisioned immediately without human intervention. Broad network access in which services can be accessed from any location at any time. Resource pooling, where several users may utilize the services simultaneously. Elasticity in which resources can be added or removed to suit the organizational needs. Measured service where clients only pay for what they have used. Using cloud with its business models it is quite easy to get healthcare services over the internet using a web browser on a range of devices like computers, laptops, mobile phones etc. 


\subsection{The need of cloud computing in health care systems.}

Most health care organizations inorder to offer a wide range of new facilities depend on workflows that consist of paper medical records, duplicate tests, film based radiological images like uv scans, X-rays etc, handwritten notes, fragmented IT systems and silos of information[4]

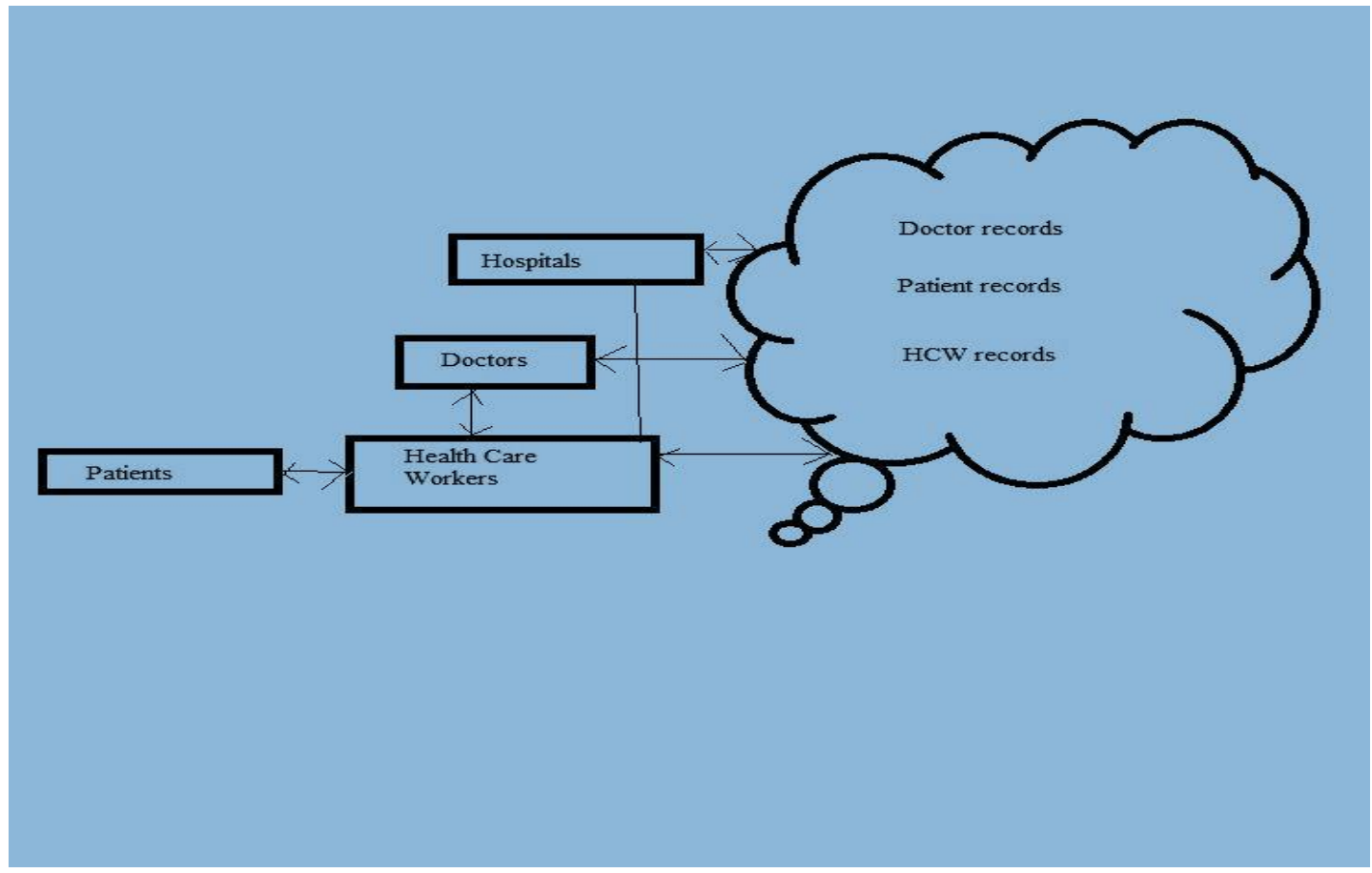

Figure 2: On-Cloud health care clinic

Information sharing across providers is inefficient and data portability is rare. care providers rely on outdated technology for their communication needs. collaboration and co-ordination of care processes is a major challenge. Today, cloud computing represents an essential opportunity to develop applications that ensure high performance data processing and easy management of the different tools in medical environment ensuring a consistent storage capability.

Figure 2 shows how the records of doctor, patient and health care workers are stored on cloud. Doctors expertise, availability, patient's diagnosis, treatment plans, health care workers training skills and their coverage area are stored on cloud. According to NIST "cloud computing is defined as a model of ubiquitous computing which provides an on-demand access to a set of resources such as network, services and storage in a flexible manner".

Proceedings of the $3^{\text {rd }}$ National Conference on Image Processing, Computing, Communication, Networking and Data Analytics (NCICCNDA 2018) 
A Survey Paper on Security Challenges in Healthcare Cloud Computing

\subsection{Impact of cloud on health care}

\subsubsection{Record and protect patients information safely}

Patients information may contain confidential pieces of data that need to be protected at all times. This is the reason why the hospitals IT infrastructure and network must be so secured from hackers.

\subsubsection{Store the data with less cost}

Cloud storage is a place where information is stored virtually, which can be used anywhere and anytime, it will have backup servers as well. Typically , so health care providers will provide this facility to their clients at a reasonable cost.

\subsubsection{Share records to authorized people}

There will be strict access scheme by the hospital system.Getting access to the hospital system is prohibited unless permitted by the doctor or physician in charge. Usually visibility and login details are not given to patients in normal cases but with the use of cloud computing, since data are available on cloud, patients can logon to the system to refer to the prescription fitted to their ailments.

\subsubsection{Less risk for data loss}

As cloud computing applications for health care will be provided with much care inorder to protect sensitive data of patients they would have constant updates which give way to raising the bar for security. While hackers are trying to get into files in the current app, the system updates its current security measures and goes for higher protection. cloud technology performs updates without causing downtime and possible data loss in real time.

\subsubsection{Mobile Component}

The usual intranet-based systems utilized in hospitals which are mostly desktop-dependent , cloud computing systems offer convenience and much mobility to its users i.e they can use the smart phones for accessing their data.

\section{Security challenges in cloud health care}

Cloud computing has raised several security threats such as data breaches, data loss, denial of service and malicious insiders that have been essentially studied and the same issues are faced by healthcare organizations. Whenever a discussion about cloud security in health care is taken place there will be very much to do for it. The cloud service provider for cloud makes sure that the customer does not face any problem such as loss of data or data theft as health records are very sensitive. There is also a possibility where a malicious user can penetrate the cloud by impersonating a legitimate patient or doctor or health care worker, there by infecting the entire cloud. This leads to affect many customers who are sharing the infected cloud The security 
and privacy features that are necessary for healthcare cloud service providers and the currently existing solutions are given in the table below.

In table 1, various security and privacy issues are briefly described with already existing solutions which can be employed for healthcare industry as well . It also gives the pros and consequences of the existing methods. This study identifies a set of categories relevant for authentication and authorization ex: public key infrastructure(PKI), X.509 certificates for user identification and authentication. As per paper [5] authorization-as-a- service(Aaas) approach can be used for health care. The IBE and IBS schemes are used for integrity maintenance, the idea is based on the identity based authorization for cloud computing along with the corresponding encryption and signature schemes without using certificates.

Trusted cloud computing platforms(TCCP) can also be used to verify the integrity of platforms as security has to be given at two levels in healthcare that is user side and provider side. Hypervisor-based cloud intrusion detection systems can be used to improve performance on data residing on virtual machines. Takabi et al, [6] introduce policy management as a service[PMaaS] to provide users with unified control point for managing policies so generic policy management can be done even for healthcare organizations on cloud. Hence The various security and privacy factors are addressed in the table 1.

Table 1: Security and Privacy Factors of healthcare cloud service providers

\begin{tabular}{|c|c|c|c|}
\hline $\begin{array}{c}\text { Security } \\
\text { Factor }\end{array}$ & Meaning & Existing Methods & Pros And Cons \\
\hline $\begin{array}{l}\text { Authenticat } \\
\text { ion and } \\
\text { Authorizati } \\
\text { on }\end{array}$ & $\begin{array}{l}\text { In healthcare the patients, } \\
\text { healthcare workers and doctors } \\
\text { should be authenticated to avoid } \\
\text { data theft as electronic health } \\
\text { records will be stored on cloud. }\end{array}$ & $\begin{array}{l}\text { User names and passwords, } \\
\text { biometric(finger, iris, face ,ECG } \\
\text { etc), HIPPA policies, } \\
\text { ABE(attribute based encryption) } \\
\text { on patient health record, } \\
\text { kerberos server authentication, } \\
\text { SEA(Secure and efficient } \\
\text { authentication using smart } \\
\text { gateways[7] }\end{array}$ & $\begin{array}{l}\text { User names and passwords } \\
\text { can be easily hacked. } \\
\text { Biometrics guarantees high } \\
\text { levels of security compared } \\
\text { to traditional user names } \\
\text { and passwords. }\end{array}$ \\
\hline $\begin{array}{l}\text { Identity and } \\
\text { access } \\
\text { managemen } \\
\text { t }\end{array}$ & $\begin{array}{l}\text { Identity management can be done } \\
\text { based on unique usernames and } \\
\text { passwords which may prone to be } \\
\text { weaklink in security when } \\
\text { transferred to cloud hence a } \\
\text { centralized control of access and } \\
\text { identities should be adopted for } \\
\text { much better performance. }\end{array}$ & $\begin{array}{l}\text { IBE(identity based encryption), } \\
\text { IBS(identity based signature), } \\
\text { role based access control, } \\
\text { dynamic risk based access } \\
\text { control, profile based access } \\
\text { control where personalization } \\
\text { attributes are used to present } \\
\text { users. Better to use "in-house" } \\
\text { private clouds. }\end{array}$ & $\begin{array}{l}\text { IBE and IBS are suited } \\
\text { only for private clouds, no } \\
\text { evidence about the } \\
\text { performance on public } \\
\text { clouds[8] }\end{array}$ \\
\hline
\end{tabular}

Proceedings of the $3^{\text {rd }}$ National Conference on Image Processing, Computing, Communication, Networking and Data Analytics (NCICCNDA 2018) 


\begin{tabular}{|c|c|c|c|}
\hline $\begin{array}{l}\text { Confidentia } \\
\text { lity, } \\
\text { Integrity } \\
\text { and } \\
\text { Availability }\end{array}$ & $\begin{array}{l}\text { Assuring the confidentiality of } \\
\text { healthcare data as they are very } \\
\text { sensitive records. Service providers } \\
\text { should ensure the availability of } \\
\text { data when needed. }\end{array}$ & $\begin{array}{l}\text { Encryption techniques, } \\
\text { Fragmentation approach to store } \\
\text { sensitive data[9], protecting the } \\
\text { database from malware and } \\
\text { various attacks using strong } \\
\text { firewalls. }\end{array}$ & $\begin{array}{l}\text { Fragmentation and } \\
\text { encryption techniques can } \\
\text { be combined to get better } \\
\text { performance[9] }\end{array}$ \\
\hline $\begin{array}{l}\text { Monitoring } \\
\text { and } \\
\text { Incident } \\
\text { Response }\end{array}$ & $\begin{array}{l}\text { Healthcare companies must be able } \\
\text { to depend on their cloud provider } \\
\text { to respond to attack with immediate } \\
\text { containment and notification and } \\
\text { provide service continouity }\end{array}$ & $\begin{array}{l}\text { SMS sent only to authorized } \\
\text { persons , GPRS techniques, } \\
\text { wireless sensors }\end{array}$ & $\begin{array}{l}\text { Sensors are used to collect } \\
\text { health data from patients } \\
\text { and contimous monitoring } \\
\text { is done, high maintenance } \\
\text { cost[10] }\end{array}$ \\
\hline $\begin{array}{l}\text { Policy } \\
\text { Managemen } \\
\text { t }\end{array}$ & $\begin{array}{l}\text { Defining and enforcing rules for } \\
\text { certain actions such as auditing or } \\
\text { proof of complaince }\end{array}$ & $\begin{array}{l}\text { Generic security management } \\
\text { framework }\end{array}$ & $\begin{array}{l}\text { Policy management as a } \\
\text { service pMaas framework } \\
\text { to give users a unified } \\
\text { control point[11] }\end{array}$ \\
\hline Privacy & $\begin{array}{l}\text { Protect personally identifiable } \\
\text { information (PII) within the cloud } \\
\text { from adversial attacks that aim to } \\
\text { find out the identity of the person } \\
\text { that PII relates to. }\end{array}$ & 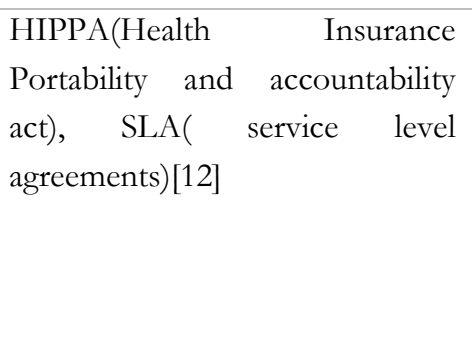 & $\begin{array}{l}\text { The issues of privacy and } \\
\text { control cannot be solved, } \\
\text { but merely assured with } \\
\text { tight service-level } \\
\text { agreements (SLAs) or by } \\
\text { keeping the cloud } \\
\text { itselfprivate. }\end{array}$ \\
\hline
\end{tabular}

\section{CONCLUSIONS}

Cloud computing is a developing auspicious way for healthcare industry. security and privacy become the most significant issues as the patient health records are very sensitive pieces of information. This paper describes few cloud computing concepts and listed few already existing techniques to ensure security and privacy and their strengths and weaknesses. Security issues could brutally affect healthcare systems on cloud infrastructure. Security should be given on both provider level as well as user level. Healthcare organizations expect a strong trustworthiness to transfer their data to the cloud. Sothere is more scope for research in the security of healthcare cloud.

\section{References}

[1] Sanjay p Ahuja, sindhu mani and jesus zambrano, "A survey of the state of cloud computing in healthcare", network and communications technologies,vol.1,no.2,2012, ISSN 1927-064X E-ISSN 1927-0658 URL: http://dx.doi.org/10.5539/nct.v1n2p12

[2] Palvinder singh, Er. Anurag jain,."survey paper on cloud computing" International journal of innovation in engineering andtechnology(ijiet),vol.3 issue 4 april 2014 issn:2319-1058, URL:https://www.researchgate.net/publication/264435521

[3] Anup H. Gade, “A survey paper on cloud computing and its effective utilization with virtualization”, international journal of scientific and engineering research, volume 4, issue 12, december 2013, issn 2229-5518 
[4] Caemelo pino, Roberto di salvo,"A survey of cloud computing architecture and applications in health”, (ICCSEE proceedings of the 2nd international conference on computer science and electronics engineering 2013), published by atlantis press ,paris, france

[5] H. Kim and S. Timm, "X.509 authentication and authorization in fermi cloud," in Utility and Cloud Computing (UCC), 2014 IEEE/ACM 7th International Conference on, pp. 732-737, Dec 2014.

[6] B. Tang, R. Sandhu, and Q. Li, "Multi-tenancy authorization models for collaborative cloudservices," in Collaboration Technologies and Systems (CTS), 2013 International Conference on, pp.132-138, May 2013.

[7] Sanaz rashmi moosavi, tuan nguyen gia , amir-mohammad rahamani "SEA :a secure and efficient authentication and authorization architecture for IOT-based healthcare using smart gateways", 6th international conference on ambient systems, networks and technologies(ANT 2015), doi:10.1016/j.procs.2015.05.013

[8] Umair mukhtar ahmed naushahi, "profile-based access control in cloud computing environments with applications in health care systems", a thesis submitted, bishops university sherbrooke,quebec, canada february 2016

[9] Sabarina De Capitani di vimercati, Robert F. Erbacher," Encryption and fragmentation for data cinfidentiality in the cloud”, “ABC4EU”(FP7-312797) 2010-2011 project “Gendata 2020(2010RTFWBH)

[10] Indhumathy N, Dr.Kiran kumar patil," Medical alert system for remote health monitoring using sensors and cloud computing", ijert:international journal of research in engineering and technology pissn:2321-7308

[11] Hassan takabi, james b.d. joshi, “ policy Management as a service:an approach to manage policy heterogeneity in cloud computing Environment”, IEEE 2012, DOI 10.1109/HICSS.2012.475

[12] Abhinay B.Angadi, Akshata B.Angadi, Karuna C.Gull "Security Issues with Possible Solutions in Cloud Computing-A Survey “,ISSN: 2278 - 1323 International Journal of Advanced Research in Computer Engineering \& Technology (IJARCET) Volume 2, Issue 2, February 2013

Proceedings of the $3^{\text {rd }}$ National Conference on Image Processing, Computing, Communication, Networking and Data Analytics (NCICCNDA 2018) 